\title{
FATIGUE LOAD MODEL FOR HIGHWAY BRIDGES IN HEAVILY LOADED AREAS OF CHINA
}

\author{
Wei-zhen $\mathrm{Chen}^{1}$, Jun $\mathrm{Xu}^{1, *}$, Bo-chong $\mathrm{Yan}^{2}$ and Zhi-ping Wang ${ }^{1}$ \\ ${ }^{1}$ Department of Bridge Engineering, Tongji University, Shanghai, China \\ ${ }^{2}$ Shanghai Donghua Local Railway Development Co., Ltd, Shanghai, China \\ *(Corresponding Author: E-mail: jxuun@tongji.edu.cn)
}

\begin{abstract}
Fatigue is one of the main factors that cause the collapse of steel bridges. Anti-fatigue design therefore draws close attention all over the world. The design must have a fatigue load model based upon native traffic load conditions. But the Chinese steel bridge design specification does not include any fatigue load model for anti-fatigue design. So it is imperative to develop the model. This paper proposes a single vehicle fatigue load model and a 5-vehicle fatigue load spectrum model, which are based upon the latest weigh-in-motion data collected from heavily loaded area of China. Taking the effects of multi-vehicle presence into account on the basis of queuing theory, the proposed fatigue load models could be easily adapted to real traffic, thus providing substantial support to the bridge structural fatigue evaluation in the heavily loaded areas of China.
\end{abstract}

Keywords: Load model, Fatigue, Highway bridge, Heavily loaded areas

DOI: $10.18057 /$ IJASC.2015.11.3.6

\section{INTRODUCTION}

The development of fatigue damage is closely related to the safety and durability of highway bridges which are dependent primarily on traffic loads the structure has experienced. The fatigue behavior and bearing capacity are greatly influenced by the coupled actions of material degradation, vehicle load and environment [1]. Thus, it is necessary to find a method for fatigue analysis that considers real traffic load history. But the research of vehicle fatigue loads is tedious, time-consuming, cost-ineffective, and, in particular, place-sensitive, making the research result for one place inapplicable to another place and therefore impracticable for construction of new bridges. Consequently, different countries have to make different vehicle fatigue load models according to their own national conditions.

The fatigue load model in BS5400 [2] is established according to the representative vehicle inflecting the worst fatigue damage to the bridges. The fatigue load model in AASHTO [3] is evolved from the load model for strength checking. Eurocode [4-6] provides 5 fatigue load models as reference. The Japanese fatigue design guideline uses the axle loads in the specifications for highway bridges to make the fatigue load model [7-8]. The parameters of these fatigue load models are all different, reflecting different characteristics of traffic in different countries. In China, however, the traffic load model for fatigue check is still a blank in the current steel bridge design code [9]. So it is high time to fill in the blank.

It is a fundamental principle that the simulated loads of a vehicle fatigue model must cause structural fatigue damage that is the closest to that caused by the actual traffic loads. Among relevant researches, Prat [10] introduced the origin of the fatigue load model adopted by Eurocode, compared precisions of various fatigue models and analyzed the impact of longitudinal and transverse multi-vehicle presence upon the fatigue calculation using the queuing theory. 
Moses [11] studied the fatigue design methods adopted by AASHTO, and exhibited the procedures of fatigue evaluation for bridge structure design and assessment. Calgaro [12] analyzed the characteristics of traffic loads on highway bridges. Laman [13] proposed a fatigue load model in accordance with the analytic results of 5 girder bridges based on traffic load investigation. He also compared the fatigue load model with standard fatigue truck adopted by AASHTO. Chotickai [14] provided the recommended fatigue load model after his study of reliability-based fatigue design method according to mass traffic survey data.

Tong et al. [15] calculated the fatigue load spectrum for urban roads in Shanghai, China. Wang et al. [16] studied the fatigue load model for elevated roads in Guangzhou, China. Man et al. [17] analyzed the load value determination for test of cable-girder anchorage zone fatigue model, and researched corresponding fatigue truck in accordance with traffic status in China and bridge design specifications in other countries. Ren et al. [18] made a preliminary study on the selection of standard fatigue load models for highway bridges in China. Chen [19] discussed the seasonal and month variation of traffic flow and proposed a 3-axle fatigue load model in line with traffic load data collected from several measuring sites in Shandong, China. Zhang et al. [20] investigated the vehicle data of Jiangyin, Humen, Nanjing No.2 and No.3 bridges in China. He then studied the load model designed for analysis of structural with short influence line as well as the simulation method of stochastic fatigue loads for analysis of structural with long influence line. Ren [21] developed a 3-axle and a 4-axle fatigue truck, on the basis of traffic on Jiangyin Yangtze River highway, Huning, Zhenluo, Jinan Yellow River No.2 bridges and Sichuan Chengnan expressway. By means of probabilistic method and the principle of equivalent fatigue damage, Zhou et al. [22, 23] developed fatigue representative trucks for various areas of Shanxi, Fujian, Nanjing, Guangdong, Hubei, Henan, Liaoning and Chongqing, where traffic investigations were carried out. At the end, adjustments are made considering the length of influence line and longitudinal and transverse multi-vehicle presence.

Yan et al. [24] conducted a comprehensive analysis of current traffic load level in China in terms of structural ultimate bearing capacity, using huge amounts of traffic data gathered from typical road sections scattered across 23 provinces, municipalities and autonomous regions of China during the time period of 2007-2011. His study indicates that the traffic load level in Guangdong province is higher than other areas. Considering all this, the weigh-in-motion traffic data measured on 3 representative roads of Guangdong in 2008 are selected as the analytic bases in this paper. Hence, the fatigue load model proposed in this paper is applicable to heavily loaded areas.

\section{STATISTICAL ANALYSIS OF TRAFFIC LOADS}

The weigh-in-motion traffic load data are collected from 3 typical highway roads in Guangdong province of China. Table 1 lists the basic information of the traffic load.

Table 1. Measuring Sites of Traffic Load

\begin{tabular}{ccccc}
\hline Sites (ABBR) & Measuring duration & Classification & $\begin{array}{c}\text { Vehicle } \\
\text { amounts }\end{array}$ & Notes \\
\hline National Road No. 107 (107) & 20/Dec/2008-26/ Dec /2008 & First class & 237,187 & 2-way 6 lanes \\
Guangshen (GE) & 20/ Dec /2008-26/ Dec /2008 & Express way & 541,778 & 2-way 6 lanes \\
Humen (HE) & 28/Aug/2008-03/Sept/2008 & Express way & 326,949 & 2-way 6 lanes \\
\hline
\end{tabular}

The current researches [25-31] show that the probability density distribution curve of gross vehicle weight usually presents an unimodal form or a multimodal form (as seen in Figure 1). According to 
the fitting analysis of various sets of function (normal, lognormal, inverse Gaussian, Weibull, Gamma, and multimodal Gaussian distribution), the stochastic characteristics of vehicle weight can be described by the function shown in

Table 2.

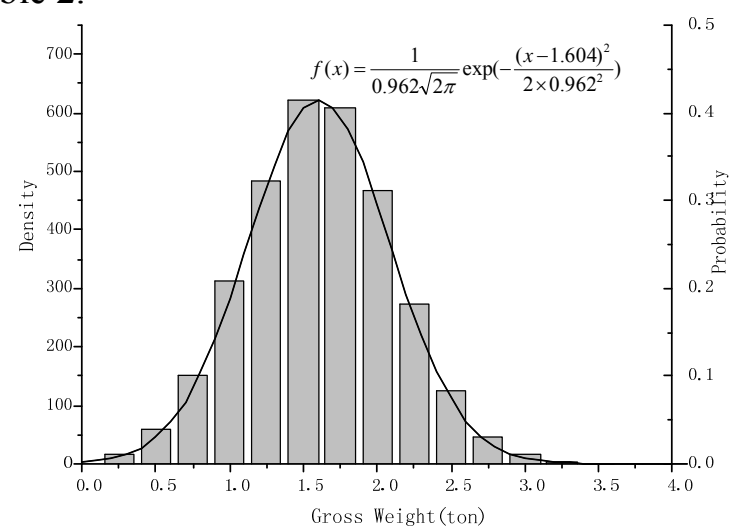

(a) Limousine Weight Distribution

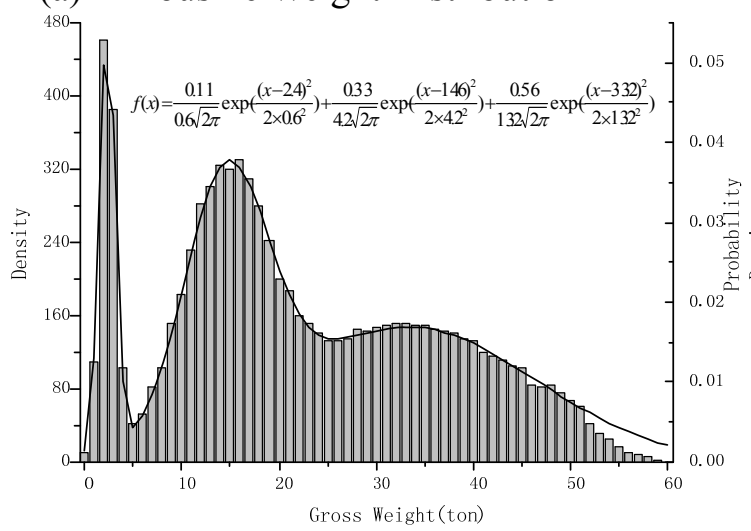

(c) 3 Axis Van Weight Distribution

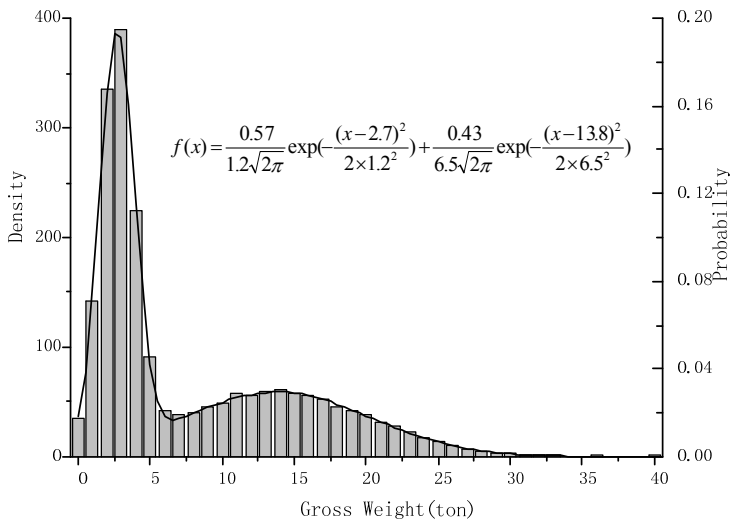

(b) 2 Axis Van Weight Distribution

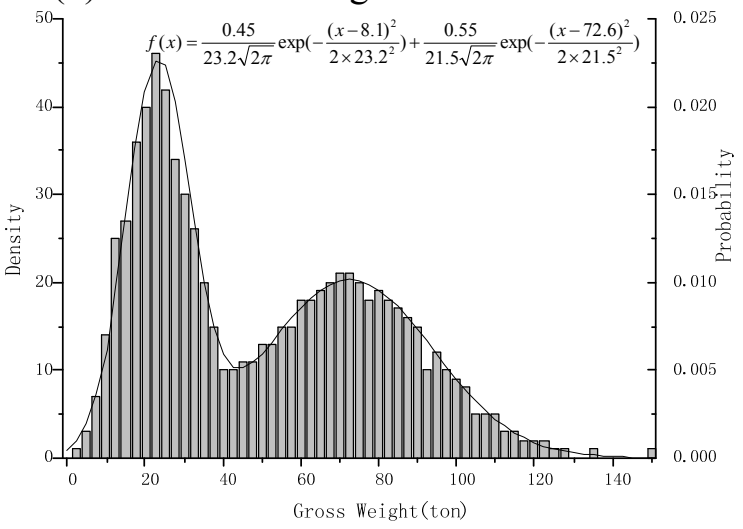

(d) 6 Axis Van Weight Distribution

Figure 1. The Probability Density Distribution of Gross Vehicle Weight at Guangshen Expressway

Table 2. Vehicle Gross Weight Density Distribution Function

\begin{tabular}{ccc}
\hline Number of axle & Vehicle type & Vehicle weight function \\
\hline 2 & $\begin{array}{c}\text { Passenger car } \\
\text { Truck }\end{array}$ & $\begin{array}{c}\text { Lognormal, Inverse Gaussian } \\
\text { Lognormal, Bimodal Gaussian }\end{array}$ \\
\hline $3-6$ & Truck & Multimodal Gaussian \\
\hline
\end{tabular}

(Note: as vehicle weight distribution of different places complies with different functions, specific mean values and standard deviation data are not provided in this table.)

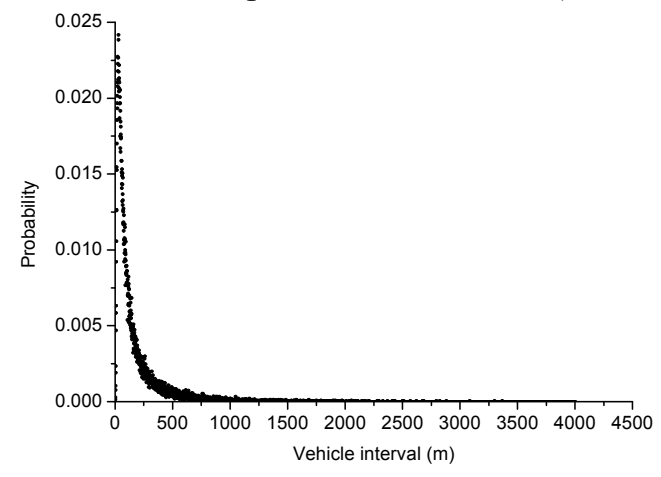


Figure 2. Statistical Histogram of Interval Between Sequent Vehicles on National Road No. 107

As far as moderate and large span bridges are concerned, the cumulative fatigue damage depends not only on gross vehicle weight and traffic volume, but also on the interval between adjacent vehicles. Therefore, key parameters affecting traffic density have been analyzed, such as traffic flow, time headway, vehicle interval (Figure 2 shows the statistical histogram of vehicle interval at National Road No. 107), vehicle speed and so on.

Shown in

Table 3 are the analytic results [26] of stochastic characteristics of traffic parameters which are basically consistent with the relevant research results from other places [12,27,29,32-34].

Table 3. Characteristics of Traffic Parameters

\begin{tabular}{cc}
\hline Item (ABBR) & $\begin{array}{c}\text { Density function type [Density distribution curve] } \\
\text { (Correlation) }\end{array}$ \\
\hline Lane speed & Normal \\
\hline Lane headway & {$[3$ curves: skew line, level line and exponential function curve] } \\
\hline Interval & Lognormal \\
\hline $\begin{array}{c}\text { Headway divided by } \\
\text { average headway within each hour (H/A) }\end{array}$ & Exponential \\
\hline $\begin{array}{c}\text { Traffic flow per hour and } \\
\text { average headway within each hour (T-A) }\end{array}$ & (Exponential function) \\
\hline $\begin{array}{c}\text { Traffic flow per hour divided by } \\
\text { average traffic flow per hour (T/A) }\end{array}$ & Uniform \\
\hline
\end{tabular}

\section{SIMULATION OF VIRTUAL TRAFFIC}

Due to the disadvantages of traffic measuring method as described before, the amount of data is small, as a result of the short duration of records listed in Table 1. Sample size enlargement is of great importance for the reliability enhancement of analytic results. The numerical technology is adopted to simulate virtual traffic stream of enough-long duration so as to reflect the stochastic variation characteristics of real traffic (as detailed in the section of statistical analysis of traffic loads).

Table 4. Vehicle Classifications

\begin{tabular}{|c|c|c|}
\hline Vehicle type & Parameters (wheel base $/ \mathrm{mm}$, axle weight $/ \%$ ) & Equivalent weight $(\mathrm{t})$ \\
\hline car/coach/2-axle truck & 6 & $8 / 18 / 20.2$ \\
\hline 3-axle truck & $43009_{140}^{3838}$ & $29.2 / 36.6$ \\
\hline 4-axle truck & 00 & $42.3 / 44.9$ \\
\hline 5-axle truck & 7000 & $62.1 / 59.0$ \\
\hline 6-axle truck & 7100 & $76.8 / 63.3$ \\
\hline
\end{tabular}

The simulation process is described as follows:

1) Both the ratio of vehicle type per hour and traffic volume per hour from every lane is acquired via traffic survey (WIM). 
2) Data from various lanes are sampled to obtain simulated group of vehicles, using Monte Carlo method.

3) To simulate space headway of vehicle group, the average headway for each lane of that hour is calculated via T-A. Then, through H/A, the headway distribution for each roadway within that hour is obtained. Finally, each space headway during that hour is computed as the product of sampled headway and speed.

4) The load space of various axles in vehicle group is determined according to space headway and the vehicle models listed in Table 4.

5) The gross vehicle weight in the vehicle group is simulated by Monte Carlo method according to the probability distribution function of vehicle weight. Axle load of various axles is then determined according to Table 4.

The vehicle type classification is shown in Table 4, which is drawn out on the basis of more than 20,000 types of on-road vehicles in China and the investigation of vehicle data collected across China [24]. The classification includes most Chinese vehicle types on highway bridges and for each type the space between axles as well as the axle weight is acquired, according to Eq. 1 and Eq. 2, respectively.

$$
W_{e j}=\left[\sum\left(f_{i} W_{i j}^{m}\right)\right]^{\frac{1}{m}}
$$

Where $W_{e j}$ denotes the $j^{\text {th }}$ equivalent axle weight of vehicle type $e ; W_{i j}$ denotes the $j^{\text {th }}$ axle weight of $i^{\text {th }}$ vehicle of type $e ; f_{i}$ denotes the occurrence frequency of $i^{\text {th }}$ vehicle of type $e ; m$ denotes the slope of fatigue $S-N$ curve.

$$
A_{e j}=\sum f_{i} A_{i j}
$$

Where $A_{e j}$ denotes the $j^{\text {th }}$ equivalent axle spacing of vehicle type $e ; A_{i j}$ denotes the $j^{\text {th }}$ axle spacing of $i^{\text {th }}$ vehicle of type $e$.

\section{SINGLE VEHICLE FATIGUE LOAD MODEL}

In this paper, the rain-flow counting method proposed by Matsuishi and Endo is employed to count stress spectrum. The fatigue damage of structural component can be quantified by Palmgren-Miner linear cumulative damage rule. The total damage $D$ is defined as the summation of damages generated by load cycles of various amplitudes, as shown in Eq. 3 .

$$
D=\sum_{i=1}^{k} \Delta D_{i}=\sum_{i=1}^{k} \frac{n_{i}}{N_{i}}
$$

Where $N_{i}$ denotes the fatigue lifetime of the $i^{\text {th }}$ load stress amplitude; $n_{i}$ denotes the actually occurring cycle times of the $i^{\text {th }}$ load stress amplitude; $k$ denotes the number of all possible amplitude value classes. 
By loading the virtual traffic flow on the structural influence line, the load effect history can be acquired. Then the corresponding fatigue damage can be calculated via Eq. 3. All the considered theoretical influence lines are listed in Table 5. The span length in the third column of Table 5, which is denoted by ' $L$ ' in the schematic diagram of the second column, is used in the calculation.

The cumulative fatigue damage of each vehicle in the simulated vehicle group can be calculated when the vehicle pass the influence line in the way of one vehicle load one time within the influence line. In the same way, the calculation of the same number of single vehicle model loading on the influence line can thus simulate cumulative damage of fatigue. The ratio of the two kinds of damage is used as analytic parameter, with ratio 1 indicating that the model can represent the real traffic flow. The parameters corresponding to typical influence lines listed in Table 5 are calculated, respectively. Then 1 is taken as the target value of the parameter, and the parameters (axle load and wheel base) of single vehicle model are modified to render the least sum of squares of differences between 1 and various parameters of influence line.

Table 5. Theoretical Influence Line for Calculation

\begin{tabular}{|c|c|c|}
\hline $\begin{array}{l}\text { Type } \\
\text { (Num) }\end{array}$ & Schematic diagram & $\begin{array}{l}\text { Span- } L \\
(\mathrm{~m})\end{array}$ \\
\hline $\begin{array}{l}\text { Simply support } \\
\text { midspan moment }(\mathrm{A})\end{array}$ & $\mathrm{L}$ & $\begin{array}{c}1.25 \\
2.5 \\
5\end{array}$ \\
\hline $\begin{array}{l}\text { 2-span continuous } \\
\text { midspan moment }(\mathrm{B})\end{array}$ & & $\begin{array}{l}10 \\
20 \\
30\end{array}$ \\
\hline $\begin{array}{l}\text { 2-span continuous } \\
\text { intermediate support moment }(\mathrm{C})\end{array}$ & $\mathrm{L}$ & $\begin{array}{c}50 \\
75 \\
100\end{array}$ \\
\hline
\end{tabular}

According to the calculation, when the influence line is long, wheel base and distribution of axle loads have less effect on fatigue damage, with various damage ratios calculated by equivalent vehicle weight all close to 1; and when the influence line is short, the wheel base and the axial ratio have more effect on fatigue damage. Also according to the calculation result, various measuring points find big differences in the vehicle load model based on the method of the least-square fatigue damage variance: different measuring points and influence lines lead to different better vehicle types, and even in the case of the same count of vehicle axles, the axle load ratio still displays big differences. But generally speaking, a single truck with 3 or 4 axles will be better. The final fatigue load models are shown in Figure 3.

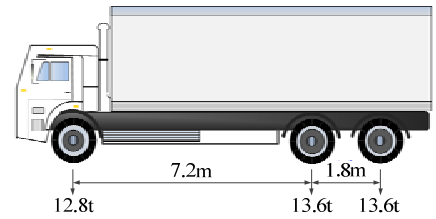

(a) 3-axle

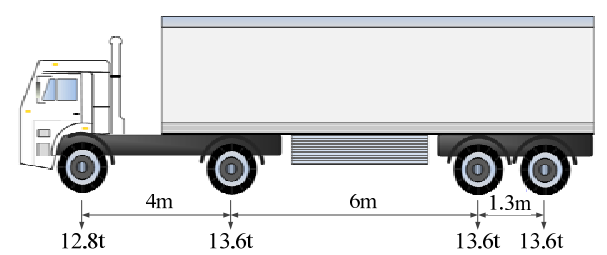

(b) 4-axle

Figure 3. Single Vehicle Fatigue Load Model

\section{VEHICLE SPECTRUM FATIGUE LOAD MODEL}

The single truck fatigue model is easy to apply, but the model is short of flexibility. Therefore, the vehicle spectrum fatigue load model is also applied. As the types of vehicle, as shown in Table 4, are too many to be directly applied in calculation, this paper chooses 5 truck types in light of axle 
numbers for vehicle spectrum. The development of vehicle spectrum fatigue load model works on the principle that the fatigue damage caused by fatigue load model is equal to that caused by real vehicle group. The 5-truck spectrum fatigue load model is shown in Table 6.

\section{ANALYSIS OF MULTI-VEHICLE PRESENCE}

When structural influence surface is large while space headway is small, multiple vehicles tend to simultaneously appear within the same influence range and structural load effects caused by individual vehicle tend to joint together. In this case, the load effect is very difference from that caused by vehicles passing one after another.

Table 6. Vehicle Spectrum Fatigue Load Model

\begin{tabular}{ccccccc}
\hline & \multicolumn{3}{c}{ Vehicle configuration } & \multicolumn{3}{c}{ Type proportion (\%) } \\
Vehicle type & Wheel base (m) & Axle weight (t) & 107 & GE & HE \\
\hline & 5.0 & $7-13$ & 66 & 63 & 57 \\
\hline
\end{tabular}

For multi-lane bridges, two aspects of multi-vehicle presence should be considered: multiple vehicles present simultaneously on the same roadway or on multiple roadways. Multi-lane bridges should be therefore designated as longitudinal and transverse multi-vehicle effects, respectively. In this paper, the queuing theory is adopted to analyze the multi-vehicle effects on fatigue damage.

Longitudinal multi-vehicle effects: passing bridge could be regarded as a service for vehicles [33], with the vehicular arrivals supposedly obeying Poisson process, with the rate parameter designated as $\lambda$ (i.e. the average traffic density-veh/s), and the stochastic duration $T$ of vehicular passing bridge supposedly complying with exponential distribution. The multi-vehicle presence on the same lane can then be managed by the queuing theory of $M / M / k / 0$ service system, whose number of service window is designated as $k$, that is, the roadway capacity of vehicle, which is defined here as the rounded ratio between the mean value of $T$ and the least value of headway $T_{s}$. For $n(n \leq k)$ vehicles simultaneously present on the same lane, the mean service (passing bridge) time of each vehicle is computed according to $T_{i}=T-i \cdot T_{s} \quad(i=1,2,3 \ldots n)$, thus generating various service rates for each vehicle. Shown in Figure 4 is the system state transition.

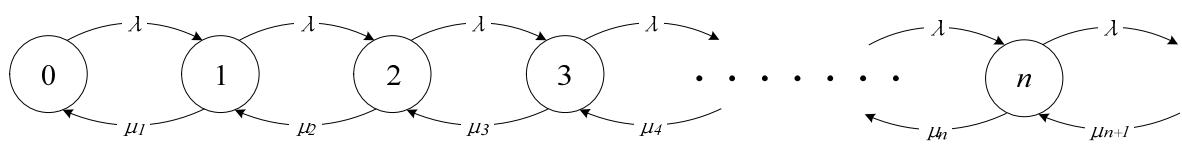

Figure 4. The Schematic Diagram of State Transition of Single Lane Service System

In Figure 4, $\mu_{n}=\alpha+\sum_{i=1}^{n} \psi_{i}, \alpha=\frac{1}{T}$ and $\psi_{i}=\frac{1}{T_{i}}$. According to the queuing theory, the probability of $n$ vehicles loading at any time on the same lane of a bridge can be described by Eq. 4 . 


$$
\begin{aligned}
& P_{n}=\left(\frac{\lambda}{\alpha}\right)^{n}\left\{1+\frac{\lambda}{\alpha}+\sum_{i=2}^{k}\left[\lambda^{i}\left(\alpha \prod_{s=1}^{i-1}\left(\alpha+\sum_{j=1}^{s} \psi_{j}\right)\right)^{-1}\right]\right\}^{-1} \quad(n=0,1) \\
& P_{n}=\left\{\frac{\lambda^{n}}{\alpha}\left[\prod_{s=1}^{n-1}\left(\alpha+\sum_{j=1}^{s} \psi_{j}\right)\right]^{-1}\right\}\left\{1+\frac{\lambda}{\alpha}+\sum_{i=2}^{k}\left[\lambda^{i}\left(\alpha \prod_{s=1}^{i-1}\left(\alpha+\sum_{j=1}^{s} \psi_{j}\right)\right)^{-1}\right]\right\}^{-1} \quad(2 \leq n \leq k)
\end{aligned}
$$

For simplification of the analysis, only one kind of vehicle type and the rectangular influence line are considered. Then, the mean occurrence number of $n$-vehicle presence on the same lane is as follows.

$$
N_{n}=\frac{P_{n}}{1-P_{0}} \frac{N}{n}
$$

Where $N$ denotes the total number of vehicles that have passed the same lane.

The adjustment factor of longitudinal multi-vehicle effect is defined as the ratio of cumulative fatigue damage between real group configuration passing and single vehicle passing along the same lane (see Eq. 6).

$$
\gamma_{k}=\sqrt[m]{\frac{P_{1}}{1-P_{0}}+\frac{P_{2}}{1-P_{0}} 2^{m-1}+\frac{P_{3}}{1-P_{0}} 3^{m-1}+\cdots+\frac{P_{k}}{1-P_{0}} k^{m-1}}
$$

Where $m$ denotes the slope of fatigue S-N curve.

Transverse multi-vehicle effects: Similarly, $\mathrm{M} / \mathrm{M} / \mathrm{k}^{\prime} / 0$ service system of queuing theory is adopted here to analyze transverse multi-vehicle effects, where $k^{\prime}$ denotes the total number of roadways. Shown in Figure 5 is the corresponding system state transition.

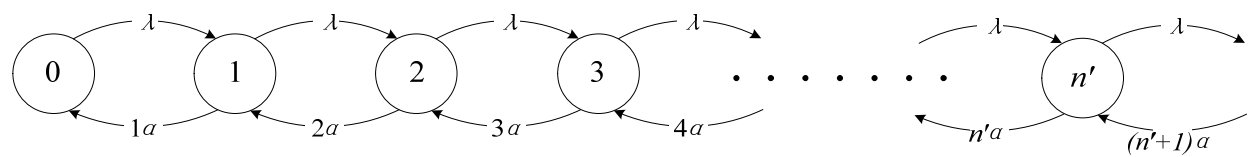

Figure 5. The Schematic Diagram of State Transition of Multi-lane Service System

In Figure 5, $\alpha=\frac{1}{T}$. The probability of $n^{\prime}\left(n^{\prime} \leq k^{\prime}\right)$ lanes occupied at the same time by a single vehicle is as follows (see Eq. 7):

$P_{n^{\prime}}=\frac{\lambda^{n^{\prime}}}{\alpha^{n^{\prime}} n^{\prime} !}\left(\sum_{i=0}^{k^{\prime}} \frac{\lambda^{i}}{\alpha^{i} i !}\right)^{-1} \quad\left(0 \leq n^{\prime} \leq k^{\prime}\right)$

Similarly, when only one kind of vehicle type and the rectangular influence line are considered, the mean occurrence number of $n^{\prime}$-vehicle present on the $n^{\prime}$ lanes is as follows (see Eq. 8):

$N_{n^{\prime}}=\frac{P_{n^{\prime}}}{1-P_{0}} \frac{N^{\prime}}{n^{\prime}}$

Where $N^{\prime}$ denotes the total number of vehicles that have passed the $n^{\prime}$ lanes.

The adjustment factor of transverse multi-vehicle effect is defined as the caused cumulative fatigue damage ratio between multiple vehicles passing side by side and single vehicle passing one after another along multiple lanes (see Eq. 9). 


$$
\gamma_{k}^{\prime}=\sqrt[m]{\frac{P_{1}}{1-P_{0}}+\frac{P_{2}}{1-P_{0}} 2^{m-1}+\frac{P_{3}}{1-P_{0}} 3^{m-1}+\cdots+\frac{P_{k^{\prime}}}{1-P_{0}} k^{\prime m-1}}
$$

Take 2-vehicle presence, the mean passing speed is $15 \mathrm{~m} / \mathrm{s}$, the least headway $T_{\mathrm{s}}$ is $1 \mathrm{~s}$, the slope of $\mathrm{S}-\mathrm{N}$ curve is 3 , and one year consists of 280 days. The following equations can then be acquired: $\lambda=\mathrm{N} / 280 / 24 / 3600=\mathrm{N} / 24192000(\mathrm{veh} / \mathrm{s}), \quad \alpha=1 / \mathrm{T}=15 / \mathrm{L} \quad$ and $\quad \psi 1=1 / \mathrm{T} 1=1 /(\mathrm{L} / 15-1) . \quad$ Thus, $\quad$ an approximately linear relationship between $\gamma_{2}$ and $N \cdot L$ can be obtained as shown by Eq. 10 .

$\gamma_{2}=1.004+0.0001 \cdot \frac{8.85 \cdot N \cdot L}{10^{6}}$

Where $L$ denotes the length of influence line (m); $N$ denotes the yearly traffic volume for a single lane (veh).

Then, an approximately linear relationship between $\gamma_{2}^{\prime}$ and $N \cdot L$ can be obtained (see Eq. 11).

$\gamma_{2}^{\prime}=1.009+0.0001 \cdot \frac{9.41 \cdot N \cdot L}{10^{6}}$

Where $N$ denotes the yearly traffic volume for a single lane (veh), and here it can be taken as the mean value of the volume on all lanes.

The above analysis is simplified, and much more complicated situations will have to be considered in future researches which may include numerical simulation of multi-vehicle effects.

\section{APPLICABILITY ANALYSIS OF FATIGUE LOAD MODEL}

In order to verify the applicability of the proposed fatigue load models, a comparison of caused fatigue damages between load model (truck model plus multi-vehicle adjustments) and virtual traffic group is conducted for various influence lines (Table 5). And the variation tendencies of ratio curves are provided in Figure 6 and Figure 7.

The fatigue damage ratio curves demonstrate that the developed load models, with influence lines longer than $40 \mathrm{~m}$, are good in applicability and conservative in nature. When influence lines are shorter than $40 \mathrm{~m}$, the curve tendencies are not so clear and an adjustment factor of 1.25 should be multiplied to consider the length effects of influence line.

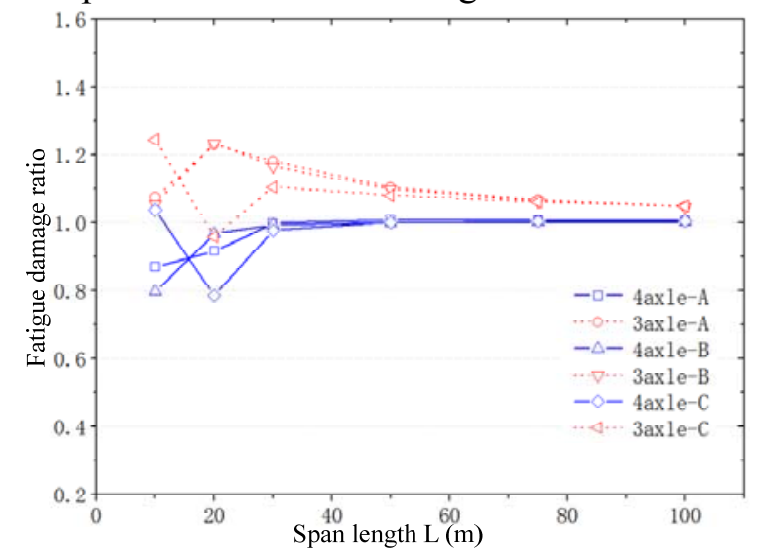

(a) National Road No. 107

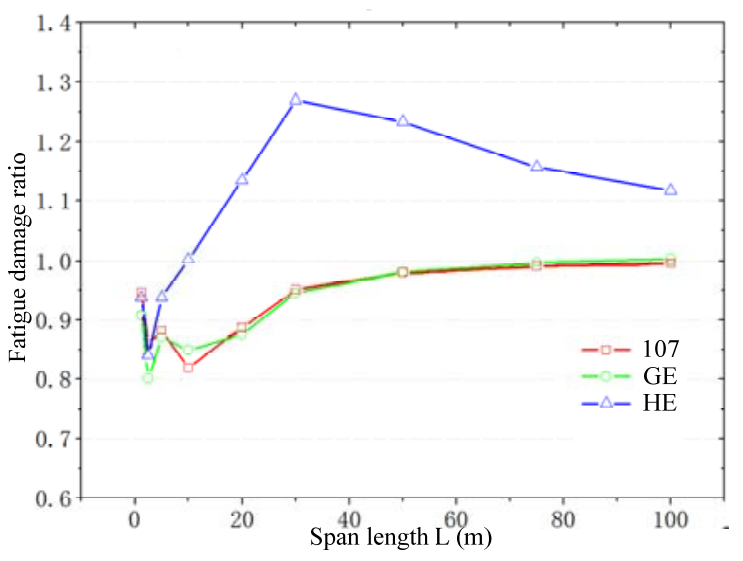

(a) Influence Line $\mathrm{A}$ 


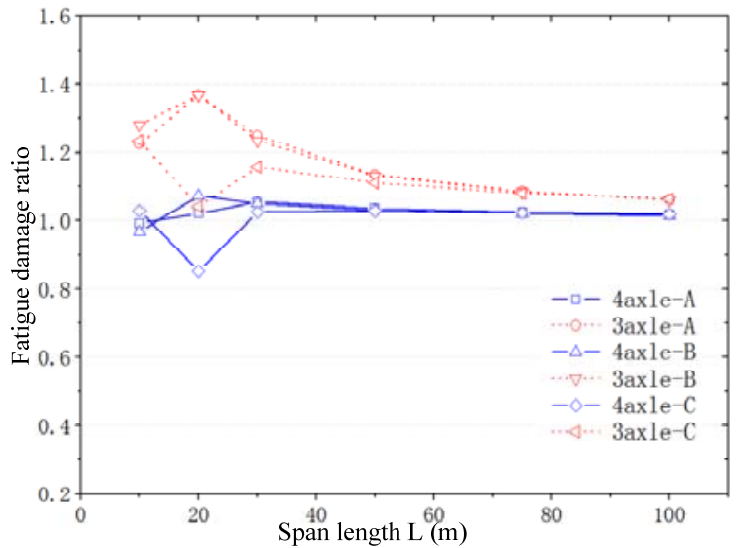

(b) Guangshen Expressway

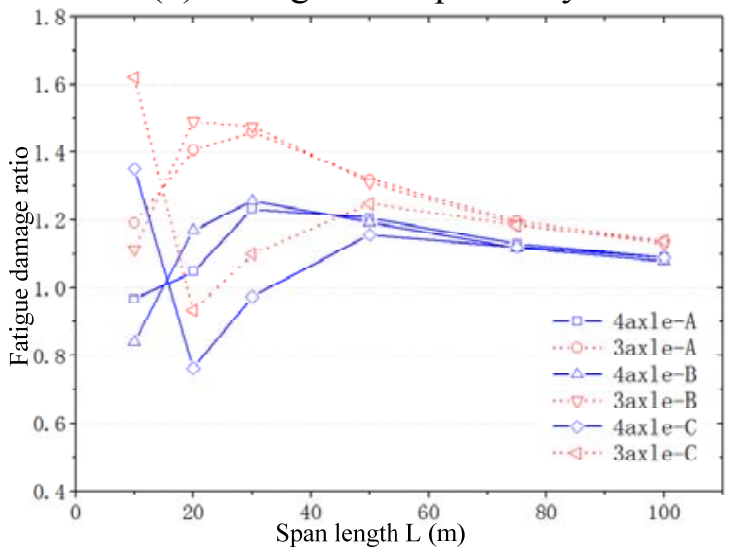

(c) Humen Expressway

Figure 6. The Damage Comparison Between Single Truck Model and Real Traffic

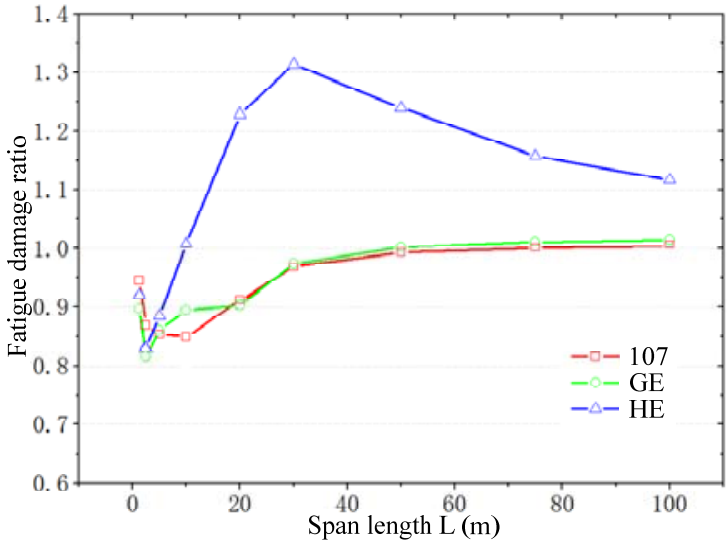

(b) Influence Line B

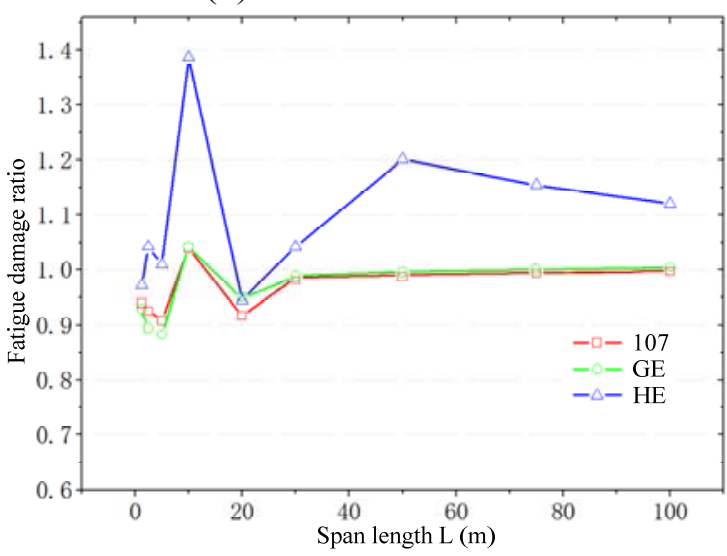

(c) Influence Line C

Figure 7. The Damage Comparison Between 5-Truck Model and Real Traffic

\section{CONCLUSIONS}

(1) This paper develops a single truck fatigue load model (3 or 4 axles) and a 5-truck spectrum fatigue load model which are based on weigh-in-motion traffic load data, virtual vehicle simulation, linear fatigue cumulative damage rule, rain-flow counting method, and typical structural influence lines.

(2) This paper has deduced computational equations for multi-vehicles according to the queuing theory and the linear fatigue damage criterion. It also proposes a multi-vehicle coefficient factor to cooperate with the fatigue load model.

(3) The traffic load data adopted in this paper is collected from the primary highway roads in Guangdong province of China, where the level of traffic loads is higher than other areas of China. Therefore, the fatigue load model provided in this paper can be well applied to other areas of China to obtain conservative calculation results.

(4) The proposed load models can generate good results in terms of fatigue damage relative to real traffic loads with influence lines longer than $40 \mathrm{~m}$. An adjustment factor of 1.25 should be multiplied for influence lines shorter than $40 \mathrm{~m}$. 
(5) The stochastic characteristics of vehicle gross weight and traffic parameters in Guangdong, China is basically similar to the relevant research findings from other studies, respecting the universal law of variation in traffic loads.

\section{REFERENCES}

[1] Sharifi, Y., "Uniform Corrosion Wastage Effects on the Load-carrying Capacity of Damaged Steel Beams", Advanced Steel Construction, 2012, Vol. 8, No. 2, pp. 153-167.

[2] British Standard, BS5400 Steel, Concrete and Composite Bridges Part 10: Code of Practice for Fatigue, 1980.

[3] American Association of State Highway and Transportation Officials, AASHTO LRFD Bridge Design Specifications (SI Units), 2007.

[4] CEN. Eurocode 1, Actions on Structures, Part 2-Traffic Loads on Bridges, BS EN 1991-2, Brussels, 2003.

[5] CEN. Eurocode 3, Design of Steel Structures, Part 2-Steel Bridges, BS EN 1993-2, Brussels, 2006.

[6] CEN. Eurocode 3, Design of Steel Structures, Part 1-9-Fatigue, BS EN 1993-1-9, Brussels, 2005.

[7] Japan Road Society. Fatigue Design Guidelines for Steel Bridges, 2002.

[8] Japan Road Society. Specifications for Highway Bridges, 2002.

[9] Ministry of Communications of PRC. Specifications for Design of Steel Structure and Timber Structure Highway Bridges and Culverts (JTJ 025-86), 1987.

[10] Prat, M., "Traffic Load Models for Bridge Design Recent Developments and Research", Progress in Structural Engineering and Materials, 2001, Vol.3, pp. 326-334.

[11] Moses, F., Schilling, C.G. and Raju, K.S., "Fatigue Evaluation Procedures for Steel Bridges", NCHRP Report 299, 1987.

[42] Calgaro, J.A., "Loads on Bridges", Progress in Structural Engineering and Materials, 1998, Vol.4, pp. 452-461.

[13] Laman, J.A., "Fatigue Load Models for Girder Bridges", Journal of Structural Engineering ASCE, 1996, Vol. 7, pp. 726-733.

[14] Chotickai, P., Fatigue Reliability Based Analysis Methods for the Evaluation of Steel Bridge Structure, Ph.D. Thesis, Purdue University, 2004.

[15] Tong, L.W., Shen, Z.Y. and Chen, Z.Y., "Fatigue Load Spectrum for Urban Road Bridges", China Civil Engineering Journal, 1997, Vol.30, No.5, pp. 20-27. (in Chinese)

[16] Wang, R.H., Chi, C. and Chen, Q.Z., et al., "Study on the Model of the Fatigue-loaded Vehicles in Guangzhou Trestle Bridges". Journal of South China University of Technology (Natural Science Edition), 2004, Vol. 32, No.12, pp. 94-96. (in Chinese)

[17] Man, H.G., Li, Q. and Tang, L., "Determination of Fatigue Load for Cable and Girder Anchorage Structure of Highway Steel Cable-Stayed Bridge", Bridge Construction, 2007, No. 3, pp. 13-16. ( in Chinese)

[18] Ren, J., Zhao, R.D. and Mao, X.M., "Study of Fatigue Load Spectrum for Highway Bridge". Sichuan Building Science, 2007, Vol.33, No.1, pp. 34-37. (in Chinese)

[19] Chen, M. "Research on Highway Bridge Fatigue Truck Model, Ph.D. Thesis, Tongji University, China, 2009. ( in Chinese)

[20] Zhang, L., Investigation and Study of Highway Bridge Loads for Fatigue Design, Ph.D. Thesis, Tongji University, China, 2009. (in Chinese)

[21] Ren, W.P., Fatigue Behavior and Fatigue Life Evaluation of Structural Details in Welded Steel Girder Bridges, Ph.D.Thesis, Southwest Jiaotong University, China, 2008. (in Chinese) 
[22] Zhou, Y.T., Zhai, H. and Bao, W.G., et al., "Research on Standard Fatigue Vehicular Load for Highway Bridges". Highway, 2009, Vol. 12, pp. 21-25. (in Chinese)

[23] Zhou, Y.T., Bao, W.G. and Zhai, H., et al., "Study of Standard Fatigue Design Load for Steel Highway Bridges", China Civil Engineering Journal, 2010, Vol. 43, No. 11, pp. 79-85. (in Chinese)

[24] Yan, B.C., Chen, W.Z. and Xu, J., "Analysis of the Current Situation of Highway Traffic Load in China", Proceedings of the First International Conference on Performance-based and Life-cycle Structural Engineering, Hong Kong, China, 2012, pp. 1278-1286.

[25] CCCC Highway Consultants Co., Ltd., "Research on Bridge Design Load and Safety Verification Load”, Research Report, 2012. (in Chinese)

[26] Tongji University, "Research on Fatigue Load Model of Highway Steel Bridge and its Technical Parameters", Volume Report of Western Transportation Construction Projects (2008 318494 04) of Chinese Ministry of Transport, 2012. (in Chinese)

[27] Bailey, S.F. and Bez, R., "Site Specific Probability Distribution of Extreme Traffic Action Effects", Probabilistic Engineering Mechanics, 1999, Vol. 14, pp. 19-26.

[28] Vu, K.A.T. and Stewart, M.G., "Structural Reliability of Concrete Bridges Including Improved Chloride-induced Corrosion Models", Structural Safety, 2000, Vol. 22, pp. 313-333.

[29] Miao, T.J., "Bridge Live Load Models With Special Reference to Hong Kong”, Ph.D.Thesis, Hong Kong Polytechnic University, Hong Kong, 2001.

[30] Gindy M., "Development of A Reliability Based Deflection Limit State for Steel Girder Bridges", Ph.D. Thesis, State University of New Jersey, New Brunswick, New Jersey, 2004.

[31] Caprani, C.C., O'Brien, E.J. and McLachlan, G.J., "Characteristic Traffic Load Effects from A Mixture of Loading Events on Short to Medium Span Bridges”, Structural Safety, 2008, Vol. 30, pp. 394-404.

[32] Crespo-Minguillón, C. and Casas, J.R., "A Comprehensive Traffic Load Model for Bridge Safety Checking”, Structural Safety, 1997, Vol. 19, No. 4, pp. 339-359.

[33] Croce, P. and Salvatore, W., "Stochastic Model for Multilane Traffic Effects on Bridges", Journal of Bridge Engineering, 2001, Vol. 6, No. 2, pp. 136-142.

[34] Miao, T.J. and Chan, T.H.T., "Bridge Live Load Models from WIM Data", Engineering Structures, 2002, Vol. 24, pp. 1071-1084. 